\title{
COVID-19 as an opportunity to reveal the impact of large hospital expansion on the healthcare delivery system: evidence from Shanghai, China
}

\author{
Yuqian Chen $^{1 \# \wedge}$, Linan Wang ${ }^{1,2 \#}$, Xin $\mathrm{Cui}^{3}$, Jiajie Xu${ }^{1}$, Yingqi $\mathrm{Xu}^{2}$, Zhonghao Yang ${ }^{4}$, Chunlin Jin ${ }^{1}$ \\ ${ }^{1}$ Department of Health Policy Research, Shanghai Health Development Research Center, Shanghai, China; ${ }^{2}$ School of Public Economics and \\ Administration, Shanghai University of Finance and Economics, Shanghai, China; ${ }^{3}$ Department of Data Service, Shanghai Information Center for \\ Health, Shanghai, China; ${ }^{4}$ Department of Finance, Shanghai Hospital Development Center, Shanghai, China \\ Contributions: (I) Conception and design: C Jin, Z Yang; (II) Administrative support: L Wang; (III) Provision of study materials or patients: X Cui; (IV) \\ Collection and assembly of data: J Xu, Y Xu; (V) Data analysis and interpretation: Y Chen; (VI) Manuscript writing: All authors; (VII) Final approval \\ of manuscript: All authors. \\ \#These authors contributed equally to this work. \\ Correspondence to: Chunlin Jin, PhD. Department of Health Policy Research, Shanghai Health Development Research Center, No. 1477 West Beijing \\ Road, Jing'an District, Shanghai 200041, China. Email: jinchunlin@shdrc.org; Zhonghao Yang, PhD. Department of Finance, Shanghai Hospital \\ Development Center, No. 2 Kangding Road, Jing'an District, Shanghai 200041, China. Email: yzhonghao249@163.com.
}

\begin{abstract}
Background: The expansion of large hospitals on the medical service market's supply side has always been an intensely debated topic. In this study, we conducted statistical analysis on the natural shock of COVID-19 to investigate whether the large hospitals will draw health demand from the small hospitals when a supply capacity surplus is present, a phenomenon otherwise known as the "siphon effect".

Methods: We collected the monthly hospital income and service data, including outpatient income, inpatient income, number of visits, and discharges, from all public hospitals, from January 2018 to July 2020 in Shanghai. A difference-in-differences (DIDs) method was applied to analyze the existence of the large hospitals' siphon effect by identifying the differences in the healthcare service market share change between large and small hospital groups at the height of pandemic (February and March, 2020) and the postpandemic period (April and May, 2020). Case mix index (CMI) was used to verify whether the reduction in healthcare amount and market share of small hospitals was due to unnecessary care.

Results: In total, 156 public hospitals, including 46 large hospitals and 110 small hospitals, with an average number of beds of 1,079.21 and 345.25, respectively, were involved in this study. At the height of the pandemic, the healthcare service volume and revenue in public hospitals in Shanghai experienced a sharp decline, especially for large hospitals and inpatient services. Compared to small hospitals at the height of the COVID-19 pandemic, large hospitals' market share decreased significantly in outpatient and inpatient services for overall and nonlocal patients $(\mathrm{P}<0.05)$. During the postpandemic period, large hospitals' market share increased significantly in outpatient and inpatient services for overall and local patients $(\mathrm{P}<0.05)$. This increase was more substantial in inpatient services.

Conclusions: Under conditions of the COVID-19 pandemic of higher care-seeking costs in the large hospitals, some of the healthcare services typically provided by large hospitals were then supplied by small hospitals. Furthermore, the siphon effect of large hospitals could be clearly observed when a supply capacity surplus was present and external constraint on patients' care-seeking behavior was absent.
\end{abstract}

Keywords: Hospital competition; supply-side competition; hierarchical medical; siphon effect

Submitted Apr 29, 2021. Accepted for publication Aug 16, 2021.

doi: 10.21037/atm-21-2793

View this article at: https://dx.doi.org/10.21037/atm-21-2793

\footnotetext{
^ ORCID: 0000-0003-1032-0991.
} 


\section{Introduction}

Hospitals have been the target of health reforms for improving efficiency, access and value, and control costs (1). In China, public hospitals are a critical part of the healthcare system, accounting for $85 \%$ of total visits in 2019. In 1949, the People's Republic of China built a three-tier healthcare system, and generally, the level of the hospital has been strictly associated with its size throughout the country.

Since healthcare reform was initiated in the 1980s, public hospitals in China have been required to balance their operating expenses and drug sales. Hence, China's marketoriented medical reform shifted hospitals from medical service providers heavily reliant on financial subsidies to profit chasers (2). This induced hospitals to establish incentives for capital-incentive investments while ignoring human capital and have driven medical staff and patients to higher-level hospitals, which has been termed the "siphon effect" of higher-level hospitals on lower-level hospitals (3). In 2017, the First Affiliated Hospital of Zhengzhou University, in central China, was the world's largest hospital, with about 10,000 beds. At least 19 super hospitals-those with more than 4,000 beds-have popped up in China in recent years.

In 2009, to resolve the issue of "too difficult and too expensive to access" in health sector, which, to some extent, associated with the profit-chasing of large public hospitals, China launched a new comprehensive healthcare reform to provide all citizens with equal access to primary healthcare (PHC) services with reasonable quality and financial risk protection (4). The new reform responded to the public discontent with government underfunding by injecting massive funding into the health sector. Many policies were implemented to deal with the profit-driven hospitals, like a zero-makeup policy on drug and medical consumables and payment for Diagnosis-Related Groups (DRG) (5). Of greater importance, however, was the reconstruction of a PHC-based integrated delivery system (6).

Unfortunately, despite the increase in funding, the share of outpatient visits at PHC centers have decreased in relation to tertiary hospitals, and the share of hospitalizations at tertiary hospitals has increased (7). In 2019 , the tertiary hospitals accounted for $40.46 \%$ of total beds, $72.16 \%$ of total medical revenue, $53.56 \%$ of total visits, and $49.49 \%$ of total discharges (8). Previous studies reported the extensive coexistence of congestion in higherlevel hospitals and idle resources in lower-level hospitals, even in the same areas in China $(3,6,7)$. This was indicative of the resource wasted and low efficiency in China's healthcare system.

The role of the large hospitals in the health delivery system is a controversial topic across the globe. Some economics-based studies support the larger hospitals' scale effect as substantial, and large hospitals have also been associated with lower prices and higher efficiency (9-12). The critical role of small hospitals has also been noted by authors. Smaller hospitals also can provide highquality, safe, care to their local population (13), and many studies have asserted that the hospital expansion in China is misguided and might harm the PHC-based integrated delivery system (14), increase health expenditure, exacerbate overtreatment, and erode the trust between patients and physicians (15), etc.

Contrary to the orientation of the PHC-based integrated delivery system, patients seem to prefer larger hospitals and their better reputation $(16,17)$. In China, this preference is also apparent, and easier to observe due to the less strict referral system and lax medical insurance restrictions $(18,19)$. As a consequence of the preference to large hospitals, those patients previously treated in small hospitals could be easily drawn to the large hospitals should the large hospitals accept them, which is the siphon effect at work. This phenomenon is partly a result of supply capacity and the scale of the hospital. Thus, it has hard to identify this siphon effect due the gradual expansion of hospitals and their supply capacity. Although, the expansion was prominent.

However, since December 2019, COVID-19 has spread extremely quickly around the world. The pandemic's tragedy has paradoxically produced an opportunity for researchers to disclose something that is difficult to identify or prove in normal conditions (20). Most Chinese hospitals, which were neither located in high-risk districts nor appointed as the specialized treatment hospital of COVID-19, suffered a huge decrease in medical service volume from 2020 February to 2020 March - the height of the COVID-19 pandemic (21-23). Thus, the pandemic suddenly created a large surplus in healthcare supply capacity in many hospitals. Under this situation, the larger hospitals' siphon effect could be more observable, and whether the poaching of health demand from small hospitals to fill the supply capacity surplus of larger hospitals could potentially be seen on a much larger scale.

In this study, based on all public hospitals' health service data in Shanghai, we constructed difference-in-difference (DID) models for the novel conditions of COVID-19 to investigate whether the larger hospitals poached health 


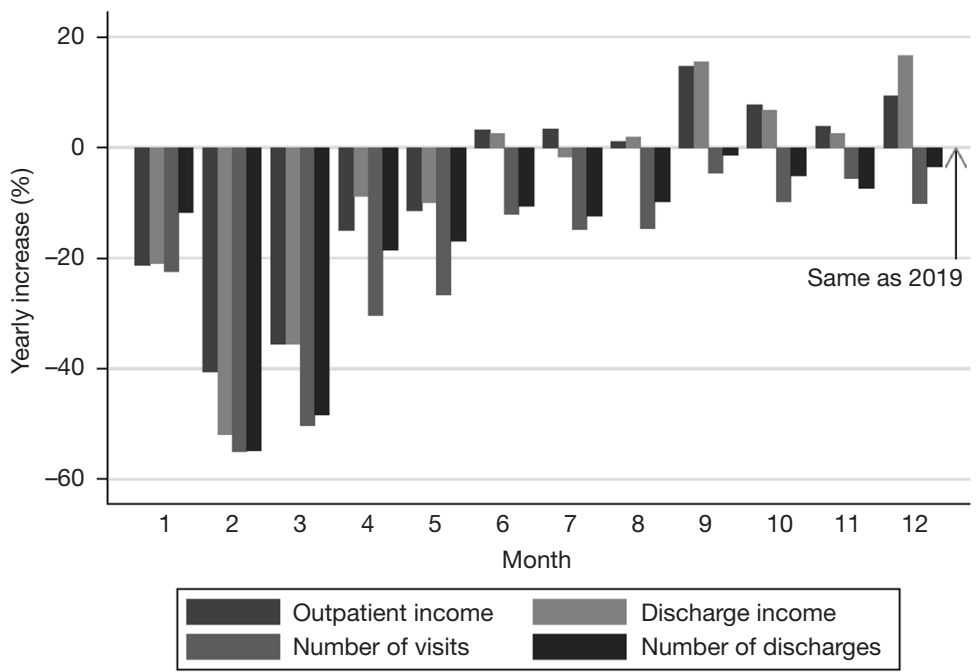

Figure 1 The public hospitals' outpatient income, discharge income, number of visits, and number of discharges, from January 2020 to December 2020, compared with the same months in 2019. The public hospitals in Shanghai suffered a terrible shock during the COVID pandemic period. The $\mathrm{X}$-axis denotes the month and the $\mathrm{Y}$-axis represent the yearly increase ratio of that value in 2020.

demand from the small hospitals.

We present the following article in accordance with the STROBE reporting checklist (available at https://dx.doi. org/10.21037/atm-21-2793).

\section{Methods}

\section{The characteristics of the bealthcare delivery system in Shanghai}

Shanghai is one of the four direct-administration municipalities of China. With 24.28 million permanent resident population, Shanghai is a center for finance, research, technology, manufacturing, transportation, and healthcare in China. By the end of 2019, there were 387 hospitals and 77.7 thousand doctors in Shanghai, servicing 171.75 million visits and 4.60 million discharges (available online: http://wsjkw.sh.gov.cn/tjsj2/20200724/6ac31287f7 $074 \mathrm{c} 869 \mathrm{f5} 63 \mathrm{fefe} 79 \mathrm{c} 75 \mathrm{~d} 3 \mathrm{html}$ ), mostly provided by large hospitals. Additionally, as a healthcare center in China, Shanghai plays a significant role in providing healthcare service to nonlocal patients (24). In 2018, Shanghai provided $6.67 \%$ visits and $29.24 \%$ discharges to nonlocal patients, accounting for $14.65 \%$ of the total expenditure, with $76.65 \%$ of the visits and $83.05 \%$ of those discharges being provided in tertiary hospitals, these are typical large hospitals in China (25).

\section{The temporary supply surplus of hospital service capacity during the COVID-19 period and study design}

Given the population mobility restrictions among the areas afflicted with the COVID-19 pandemic (26), the healthcare volume of tertiary hospitals decreased more than the other lower-level hospitals, especially for the nonlocal types. In our previous study, we have found that, from February 2020 to May 2020 in public hospitals in Shanghai, the number of visits and discharges of all public hospitals fell dramatically, compared to the same months in 2019 (Figure 1). Consequently, the pandemic lead to a sudden and massive healthcare supply capacity surplus for all public hospitals in Shanghai (27).

To explore the siphon effect of large hospitals, we divided the all hospitals into two groups according to each hospital's grade information on January 2020: the large group (tertiary) and the small group (nontertiary). In Shanghai, the tertiary hospitals were given more resources and more helpful policies as compared to the small hospitals.

The market shares of hospitals of each were relatively stable before the sudden shock brought by the COVID-19 pandemic. Thus, the market share change at the height of the COVID-19 pandemic of the large hospitals, compared to the small ones, was investigated to identify the market share change under a sudden shock with certain control measures. Further, as siphon effect only can be clearly 
observed with a substantial height difference between top and bottom of the down pipe, the poaching behavior of large hospitals from the small hospitals can be better observed with a substantial healthcare supply capacity surplus in the large hospitals and no specific restriction, like mobility control measures, on the patients' selection (like water in the pipe). Thus, the treatment group was identified to be the large hospitals during the postpandemic period, considered to be between April 2020 and May 2020 in this study, according to the schedule of COVID-19 control measures in China.

\section{Hospitals selected and data source}

We chose all public hospitals [159] as the basic sample used in this research from 387 hospitals in Shanghai. These hospitals were chosen because the public hospital is the main player in the healthcare market in China $(3,6)$. These public hospitals accounted for $89.10 \%$ of total visits and $89.64 \%$ of the hospitalization service in 2019 in Shanghai. Each public hospital has 566.19 mean beds, and there are 23 hospitals with at least 1,000 beds. Furthermore, to guarantee the data quality and consistency of measurement methods, hospitals with noncontinuous data from January 2018 to July 2020 were excluded.

To determine the presences of the siphon effect, or to verify whether the large hospitals poached patients from the small hospitals, longitudinal monthly hospital healthcare service data from January 2018 to July 2020 were examined. All hospitals' data were collected from the China Statistical Survey of Health Resources and Services Program (SHRSP), which has kept records of monthly hospital economic operation data from 2007 onward (http://www.nhc.gov.cn/ bgt/pw10709/200709/c2f58da8d8754fe09f3b364da335b9 5 f.shtml). We obtained the data from Shanghai Municipal Health Commission.

\section{Outcomes measurement}

The market shares of healthcare service indicators, including outpatient income, discharge income, numbers of visits, and discharges of each hospital in each month, were used as the outcome indicators for the allocation of patients in the healthcare service market. The market share of a specific hospital-month indicator was expressed as the hospital's level percentage of all hospitals. Due to the different care-seeking preferences and the interprovince population mobility control policies, we collected those market-share indicators from local and nonlocal patients.

\section{Statistical analysis}

DID models were constructed to analyze the large hospitals' characteristic effect on the healthcare delivery system at the height of the COVID-19 pandemic. The change was identified by the differences in market share change between the large and small hospitals. Based on our data source, the DID model study was constructed as follows:

$R S_{i, t}=\alpha_{i}+\beta_{1}$ treat $_{i}+\beta_{2}$ pandemic $_{t}+\beta_{3}$ treat $_{i}{ }^{*}$ pandemic $_{t}+\beta_{4}$ type $_{i}+\lambda_{t}+\mu_{i}+\varepsilon_{i, t}, i=h_{m}$

treat $_{i}=\left\{\begin{array}{l}=1 \text { if hospital } h \text { belongs to large group for individual } h_{m} \\ =0 \text { otherwise }\end{array}\right.$

pandemic $_{t}=\left\{\begin{array}{l}=1 \text { if } t=2020 \\ =0 \text { otherwise }\end{array}\right.$

$h=$ hospital id, $h \in[1,159]$

$m=$ month id, $m \in[2,3]$

$t=$ year id,$t \in[2018,2019,2020]$

where $R S_{i, t}$ stands for a series of the outcome indicators mentioned above. The outcome indicators in different hospitals in the same month were taken as different individuals to eliminate the monthly effect in the healthcare market. Treat $_{i}$ is a dummy variable that has a value of 1 if a sample belongs to the large hospitals group; pandemic $c_{t}$ is an indicator variable for which a value of 1 indicates the worst period of COVID-19 in China, specifically February 2020 to March 2020. The key explanatory variable was treat $_{i}{ }^{*}$ pandemic $_{t}$, which denotes the sample belonging to the large hospitals and being afflicted by the Nationwide spread of COVID-19 pandemic. The associate parameter $\beta_{3}$, denotes the relative changes of the market share of large hospitals compared to the small ones under the epidemic's

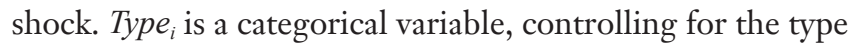
of each hospital. In this study, the hospitals were divided into three categories: general hospitals, traditional Chinese medicine (TCM) hospitals, and specialized hospitals. Thus, in the process of regression, the variable type $e_{i}$ is replaced by two dummy variables.

A similar set of DID models was used to verify whether the large hospitals poach patients from the small hospitals via an analysis of the differences between the market share changes of large and small hospitals during the postpandemic period, that is, from April 2020 to May 2020. The basic models were built as follows: 
$R S_{i, t}=\alpha_{i}+\beta_{1}$ treat $_{i}+\beta_{2}$ ppandemic $_{t}+\beta_{3}$ treat $_{i}{ }^{*}$ ppandemic $_{t}+\beta_{4}$ type $_{i}+\lambda+\mu_{i}+\varepsilon_{i, t}, i=h_{m}$

$R S_{i, t}$,reat $_{i}$, type $i, i$, and $k$ have the same denotations as in Eq. [1]. The month id $m$ indicates April and May in Eq. [2]. The ppandemic is $_{t}$ the postpandemic period, which refers to 2020 in this study. Thus, the parameter $\beta_{3}$, which is associated with the key explanatory variable, treat $_{i}{ }^{*}$ ppandemic $_{t}$, represents the large hospitals' market share changes after the widespread national pandemic as compared to the small ones.

Additionally, an alternative explanation for the increase in the large hospitals' market share during the postpandemic period is that the market share reduction of small hospitals might have occurred due to the decrease in unnecessary medical services, and not due to the siphon effect of large hospitals. Generally, medical services provided by small hospitals are less complicated and more likely to be unnecessary. In this study, the case mix index (CMI), which reflects the diversity, clinical complexity, and resource needs of all the hospitalizations of each hospital, was used to investigate the market share's association with the reduction of unnecessary medical services (28).

A parallel trend is a key assumption that enables DID to account for unobserved variables $(29,30)$. We were limited to examining only 3 years in this study, and probing into other sample periods before the beginning of the COVID-19 was not deemed feasible. Instead, to characterize the trend before the pandemic, we plotted the market share of the large and small hospital groups from January 2018 to July 2020.

A value of less than 0.05 was considered statistically significant. The Stata software version 16 for Windows (StataCorp, College Station, TX, USA) was used for statistical analysis.

\section{Ethical statement}

The study was conducted in accordance with the Declaration of Helsinki (as revised in 2013). The study was approved by the registration number of Medical Ethics Committee of Shanghai Health Development Research Center (No. 2021002). The need for written patient consent was waived because of the observational nature of this study, the subject can no longer be found, and the research project does not involve personal privacy or commercial interests.

\section{Results}

\section{Characteristics of the study hospitals and the shock of the COVID-19 pandemic}

Among all public hospitals in Shanghai, three hospitals were excluded due to the noncontinuous data. Among the total of 156 hospitals, 46 tertiary hospitals were placed into a large hospital group, and 110 nontertiary hospitals were allocated into a small hospital group. The average number of beds of large hospitals $(1,079.21 \pm 21.79)$ was much higher than that of the small hospitals $(345.35 \pm 6.10)$, which strongly supports our group classification. Among the large hospitals, 24 (52.17\%) were general hospitals, 6 (14\%) were TCM hospitals, and 16 (53\%) were specialized hospitals. Additionally, the small hospitals included a lower ratio of general hospitals $(43,39.09 \%)$ and a higher ratio of specialized hospitals $(53,48.18 \% ; \mathrm{P}<0.01)$. Furthermore, 4,836 hospital month year observations were included in this study.

Overall, after the COVID-19 outbreak, both the healthcare service volume and revenue experienced a sharp decline for public hospitals in Shanghai, especially in February 2020 and March 2020, at the height of the pandemic (Figure 1). Healthcare revenues did not recover until June 2020, while healthcare volume did not recover for the entirety of 2020 .

Specifically, at the height of COVID-19 in China (February 2020 to March 2020), all public hospitals in Shanghai suffered severe shock. The hospitals' average decrease percentage in total medical revenue, outpatient income, number of visits, discharge income, and number of discharges ranged from $34.03 \%$ to $47.3 \%$, while the large hospitals' reduction ratios were significantly higher than those of the small hospitals $(\mathrm{P}<0.05$; Table 1$)$. Notably, the average change percentage of the market share of those hospitals was positive. That is, for most hospitals, their market share increased during this period. This means, most small-scale hospitals' market share increased, while a smaller portion of large-scale hospitals' market share decreased. For the market share of the number of visits, discharge income, and number of discharges, the small hospitals' average increase rate was significantly higher than that of the large hospitals $(\mathrm{P}<0.05)$.

Conversely, during the postpandemic period (April 2020 to May 2020), the recovery of healthcare services in large hospitals was better than that of the small hospitals, 
Table 1 The average month health service outcomes change percentage of sample hospitals in the pandemic (February 2020 to March 2020) and postpandemic (April 2020 to May 2020) period in 2020 compared to the corresponding month in 2019

\begin{tabular}{|c|c|c|c|c|}
\hline Outcome variables & All hospitals $(n=156)$ & Large hospitals $(n=46)$ & Small hospitals $(n=110)$ & $P$ value \\
\hline Total medical revenue & $-37.96(28.08)$ & $-42.56(18.93)$ & $-36.04(30.95)$ & 0.06 \\
\hline Outpatient income & $-34.03(30.84)$ & $-36.96(18.59)$ & $-32.81(34.66)$ & 0.28 \\
\hline Number of visits & $-46.33(24.01)$ & $-51.28(14.54)$ & $-44.27(26.75)$ & 0.02 \\
\hline Number of discharges & $-47.3(23.06)$ & $-52.7(15.04)$ & $-44.77(25.62)$ & 0.01 \\
\hline Market share of outpatient income & $5.07(49.8)$ & $0.19(29.7)$ & $7.11(56.02)$ & 0.27 \\
\hline Market share of number of visits & $11.81(52.22)$ & $0.79(29.8)$ & $16.4(58.55)$ & 0.02 \\
\hline Market share of discharge income & $17.03(49.9)$ & $-0.47(36.75)$ & $25.4(53.18)$ & $<0.01$ \\
\hline Outpatient income & $-13.36(21.66)$ & $-10.59(13.29)$ & $-14.51(24.24)$ & 0.15 \\
\hline Number of visits & $-25.94(17.09)$ & $-24.18(10.21)$ & $-26.67(19.22)$ & 0.25 \\
\hline Discharge income & $-10.57(22.64)$ & $-9.55(14.05)$ & $-11.05(25.78)$ & 0.60 \\
\hline Number of discharges & $-22.14(19.83)$ & $-14.73(11.42)$ & $-25.61(21.9)$ & $<0.01$ \\
\hline Market share of outpatient income & $-0.79(24.81)$ & $2.37(15.12)$ & $-2.11(27.8)$ & 0.15 \\
\hline Market share of number of visits & $0.56(23.22)$ & $2.95(13.72)$ & $-0.43(26.15)$ & 0.25 \\
\hline Market share of discharge income & $-1.78(24.88)$ & $-0.66(15.42)$ & $-2.31(28.33)$ & 0.61 \\
\hline
\end{tabular}

according to the average change percentage, although this difference was only significant in regard to the number of discharges $(\mathrm{P}<0.01)$. The market share of each hospital began to restore to 2019 levels at this time. Furthermore, large hospitals' market share increased (positive average change percentage) compared to the same month in 2019, while that of the small hospitals decreased. This may indicate that the large hospitals began to poach the market share from the small hospitals.

Overall, the difference in change of number of discharges between large hospitals and small hospitals was the largest and most significant across the pandemic and postpandemic period.

\section{The large hospitals suffered more than the small hospitals during the pandemic period}

Table 2 presents the estimated impacts of the COVID-19 pandemic on the large hospitals' market share in comparison to the smaller ones. There were 156 hospitals in 2 specific months (February and March) across 3 years (2018, 2019, 2020) involved in the random effect model. Compared to the general hospitals, TCM and specialized hospitals were associated with lower market share; meanwhile, large hospitals were associated with a higher market share in total medical revenue (Table S1), outpatients, and discharge $(\mathrm{P}<0.05)$; the market shares across the hospitals did not change significantly during the height of the COVID-19 pandemic period; and, at the height of the COVID-19, the large hospitals suffered more severe shock compared to the small hospitals.

In terms of the outpatient service during the COVID-19 pandemic, the large hospitals' experienced a significantly reduced market share of the outpatient income from the nonlocal patients $(-0.03 ; \mathrm{P}<0.01)$, and the share of visit numbers from three sources (total, local and nonlocal: 
Table 2 The COVID-19 pandemic's effect on the public hospital services' market shares (156 hospitals examined in February and March in 2018, 2019, and 2020)

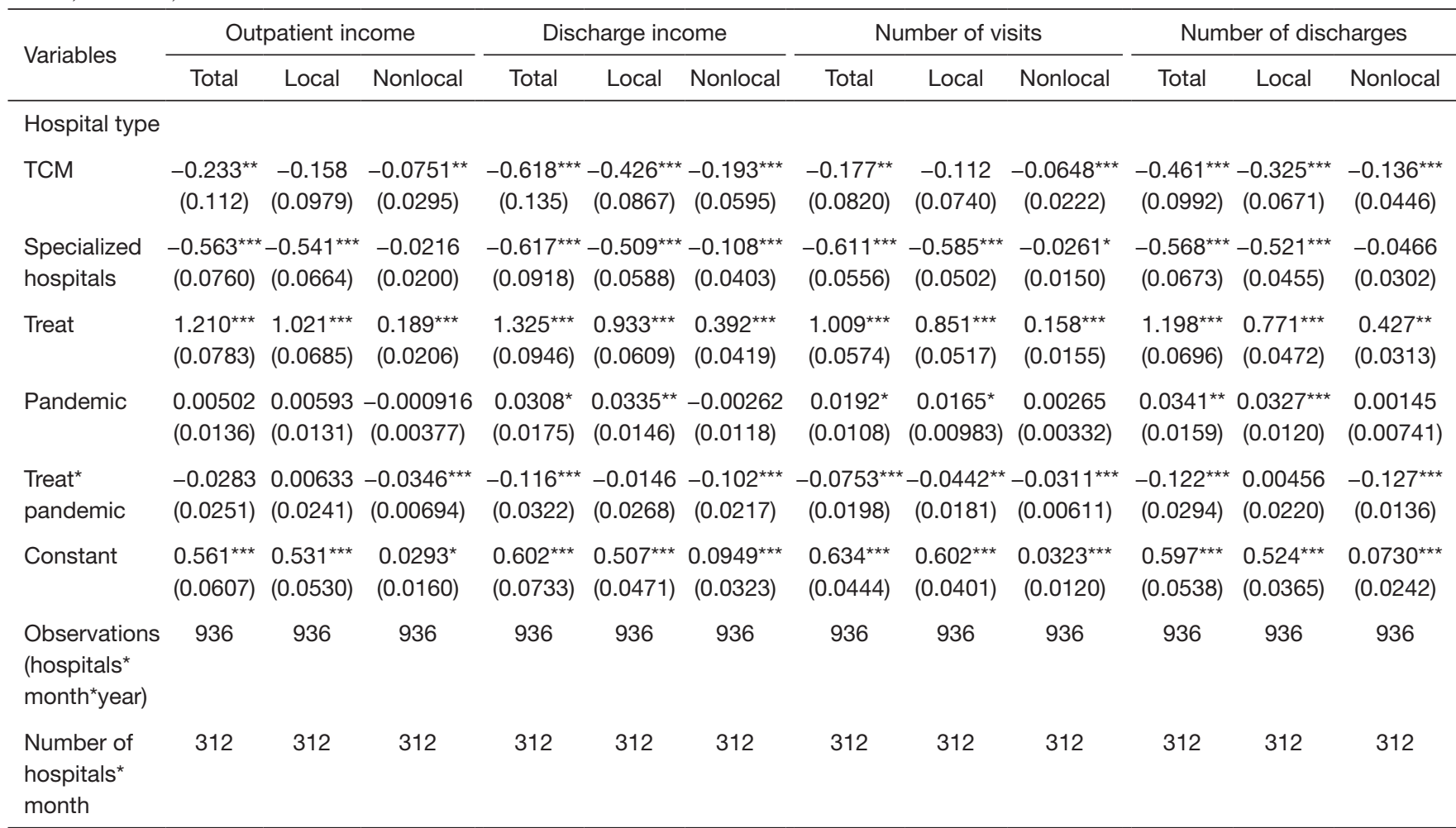

Standard errors in parentheses. * $\mathrm{P}<0.1 ;{ }^{* \star}, \mathrm{P}<0.05 ;{ }^{* \star \star}, \mathrm{P}<0.01$. * (in first column) means interaction operator. TCM, traditional Chinese medicine.

$-0.08,-0.04,-0.03 ; \mathrm{P}<0.05)$, as compared to the small hospitals. Similarly, the COVID-19 pandemic significantly reduced the large hospitals' market shares of discharges of all patients and nonlocal patients, but not that of local patients. More specifically, the COVID-19 pandemic significantly cut down the large hospitals' market share of discharge income in all patients $(-0.12, \mathrm{P}<0.01)$ and nonlocal patients $(-0.10, \mathrm{P}<0.01)$. The same effect was observed in the discharge numbers, with the large hospitals' market share decreasing both for overall $(-0.12, \mathrm{P}<0.01)$ and nonlocal $(-0.13, \mathrm{P}<0.01)$ patients.

In brief, the COVID-19 induced a more severe shock to the large hospitals compared to the small hospitals, and the shock was more severe for the discharge services and the nonlocal patients, which are more typically provided by large hospitals.

\section{The large hospitals poached patients from the small hospitals during the postpandemic period}

The estimated effect of the postpandemic on public hospitals' market shares is displayed in Table 3. There were 156 hospitals in 2 specific months (April and May) in 3 years $(2018,2019,2020)$ involved in the random effects model. Similar to the analysis in the height of the pandemic, compared to the general hospitals, the TCM and specialized hospitals were more likely to have a lower market share, while large hospitals were more likely to have a higher market share. However, what we should draw attention to is that the postpandemic situation significantly increased the large hospitals' market share of outpatient income, the number of visits and discharges $(\mathrm{P}<0.05)$ and the medical revenue $(\mathrm{P}<0.05$; Table $\mathrm{S} 2)$.

According to the statistical analysis, during the postpandemic period, large hospitals had an average $0.03 \%(\mathrm{P}<0.01)$ and $0.02 \%(\mathrm{P}<0.05)$ increase in monthly market share in outpatient income for total and nonlocal patients, as compared to the same months in previous years. Furthermore, there was a rise in large hospitals' market share of visit numbers in all patients $(0.03 \% ; \mathrm{P}<0.01)$ and local patients $(0.03 \% ; \mathrm{P}<0.05)$. The postpandemic situation, on average, significantly increased the large hospitals' 
Table 3 The COVID-19 postpandemic effect on public hospital services market shares (156 hospitals examined in April and May in 2018, 2019, and 2020)

\begin{tabular}{|c|c|c|c|c|c|c|c|c|c|c|c|c|}
\hline Variables & \multicolumn{3}{|c|}{ Outpatient income } & \multicolumn{3}{|c|}{ Discharge income } & \multicolumn{3}{|c|}{ Number of visits } & \multicolumn{3}{|c|}{ Number of discharges } \\
\hline \multicolumn{13}{|l|}{ Hospital type } \\
\hline $\begin{array}{l}\text { Specialized } \\
\text { hospitals }\end{array}$ & $\begin{array}{c}-0.514^{\star \star *} \\
(0.0811)\end{array}$ & $\begin{array}{c}-0.488^{\star * *} \\
(0.0698)\end{array}$ & $\begin{array}{l}-0.0262 \\
(0.0225)\end{array}$ & $\begin{array}{c}-0.562^{\star \star \star} \\
(0.0601)\end{array}$ & $\begin{array}{c}-0.526^{\star \star *} \\
(0.0534)\end{array}$ & $\begin{array}{c}-0.0352^{\star \star} \\
(0.0178)\end{array}$ & $\begin{array}{c}-0.613^{\star \star \star} \\
(0.0984)\end{array}$ & $\begin{array}{c}-0.495^{\star \star \star} \\
(0.0605)\end{array}$ & $\begin{array}{l}-0.118^{\star \star} \\
(0.0460)\end{array}$ & $\begin{array}{c}-0.563^{\star \star \star} \\
(0.0711)\end{array}$ & $\begin{array}{c}-0.499^{\star * *} \\
(0.0431)\end{array}$ & $\begin{array}{c}-0.0635^{\star} \\
(0.0367)\end{array}$ \\
\hline Treat & $\begin{array}{l}1.251^{\star \star *} \\
(0.0831)\end{array}$ & $\begin{array}{l}1.043^{\star \star \star} \\
(0.0716)\end{array}$ & $\begin{array}{l}0.209^{\star * \star} \\
(0.0232)\end{array}$ & $\begin{array}{l}1.051^{\star \star *} \\
(0.0616)\end{array}$ & $\begin{array}{l}0.872^{\star * \star} \\
(0.0548)\end{array}$ & $\begin{array}{l}0.179^{\star * *} \\
(0.0183)\end{array}$ & $\begin{array}{l}1.377^{\star \star \star} \\
(0.101)\end{array}$ & $\begin{array}{l}0.952^{\star * \star} \\
(0.0622)\end{array}$ & $\begin{array}{l}0.425^{\star \star \star} \\
(0.0473)\end{array}$ & $\begin{array}{l}1.224^{\star \star *} \\
(0.0730)\end{array}$ & $\begin{array}{l}0.754^{\star \star *} \\
(0.0445)\end{array}$ & $\begin{array}{l}0.470^{\star \star \star} \\
(0.0377)\end{array}$ \\
\hline Ppandemic & $\begin{array}{l}-0.0125^{\star} \\
(0.00642)\end{array}$ & $\begin{array}{l}-0.0123^{*} \\
(0.00644)\end{array}$ & $\begin{array}{c}-0.000225 \\
(0.00411)\end{array}$ & $\begin{array}{l}-0.0109^{*} \\
(0.00592)\end{array}$ & $\begin{array}{l}-0.0126^{\star \star} \\
(0.00609)\end{array}$ & $\begin{array}{c}0.00166 \\
(0.00265)\end{array}$ & $\begin{array}{l}-0.00504 \\
(0.00684)\end{array}$ & $\begin{array}{l}-0.00149 \\
(0.00918)\end{array}$ & $\begin{array}{l}-0.00355 \\
(0.00838)\end{array}$ & $\begin{array}{c}-0.0216^{\star \star} \\
(0.00867)\end{array}$ & $\begin{array}{c}-0.0129 \\
(0.00877)\end{array}$ & $\begin{array}{c}-0.00870^{*} \\
(0.00455)\end{array}$ \\
\hline $\begin{array}{l}\text { Treat }^{\star} \\
\text { ppandemic }^{*}\end{array}$ & $\begin{array}{c}0.0346^{\star * *} \\
(0.0118)\end{array}$ & $\begin{array}{c}0.0195 \\
(0.0119)\end{array}$ & $\begin{array}{l}0.0151^{\star *} \\
(0.00756)\end{array}$ & $\begin{array}{c}0.0281^{\star \star \star} \\
(0.0109)\end{array}$ & $\begin{array}{l}0.0274^{\star *} \\
(0.0112)\end{array}$ & $\begin{array}{l}0.000777 \\
(0.00489)\end{array}$ & $\begin{array}{c}0.0113 \\
(0.0126)\end{array}$ & $\begin{array}{c}0.0268 \\
(0.0169)\end{array}$ & $\begin{array}{l}-0.0154 \\
(0.0154)\end{array}$ & $\begin{array}{c}0.0685^{\star * \star} \\
(0.0160)\end{array}$ & $\begin{array}{c}0.0796^{\star \star \star} \\
(0.0161)\end{array}$ & $\begin{array}{l}-0.0111 \\
(0.00838)\end{array}$ \\
\hline $\begin{array}{l}\text { Observations } \\
\text { (hospitals* } \\
\text { month*year) }\end{array}$ & 936 & 936 & 936 & 936 & 936 & 936 & 936 & 936 & 936 & 936 & 936 & 936 \\
\hline $\begin{array}{l}\text { Number of } \\
\text { hospitals* } \\
\text { month }\end{array}$ & 312 & 312 & 312 & 312 & 312 & 312 & 312 & 312 & 312 & 312 & 312 & 312 \\
\hline
\end{tabular}

Standard errors in parentheses. * $\mathrm{P}<0.1 ;{ }^{\star \star}, \mathrm{P}<0.05$; ${ }^{\star \star \star}, \mathrm{P}<0.01 .{ }^{*}$ (in first column) means interaction operator. TCM, traditional Chinese medicine.

market share in the number of discharges for all patients $(0.07, \mathrm{P}<0.01)$ and local patients $(0.08, \mathrm{P}<0.01)$, while there was no significant impact on the market share of nonlocal patients in the discharge numbers.

\section{CMI of large and small hospitals during and after the pandemic}

One alternative explanation for the dramatic decline in healthcare volume and healthcare revenue for hospitals to the siphon effect during the pandemic is that people cut down use of unnecessary healthcare services to avoid getting infected in crowded hospitals. This is consistent with the increase in use of internet hospitals and the rise in long-term prescriptions in Shanghai. To test whether this decline was due to the limiting of unnecessary healthcare services, we compared the average CMI from January to October between 2019 and 2020, in large hospitals and small hospitals. If unnecessary medical service use reduced, the CMI in 2020 should have increased significantly.

According to the $t$-test, there was no significant difference in CMI between 2019 and $2020(\mathrm{P}=0.53)$. Specifically, the average CMI of large hospitals was 1.00 in 2019 and 1.03 in 2020; the average CMI of small hospitals was 0.74 in 2019 and 0.76 in 2020 . Both groups' average CMI increased in 2020 compared to 2019. However, this increase was not significant $(\mathrm{P}=0.72$ vs. $\mathrm{P}=0.48$; Figure 2). The increase in ratio of small hospitals $(3.08 \%)$ was a little bit higher than that of large hospitals (2.43\%).

\section{Robustness}

A potential challenge to the DID strategy was that differential changes between large and small hospitals could have driven by preexisting differences in the time trends of the outcomes. The market share for healthcare services from January 2018 to July 2020 for large hospitals and small hospitals was depicted in Figure 3. Patients were divided into local and nonlocal groups. According to Figure 3, from January 2018 to July 2020, the average market share of each hospital group was relatively stable both for the overall and the local patients, especially for the number of 

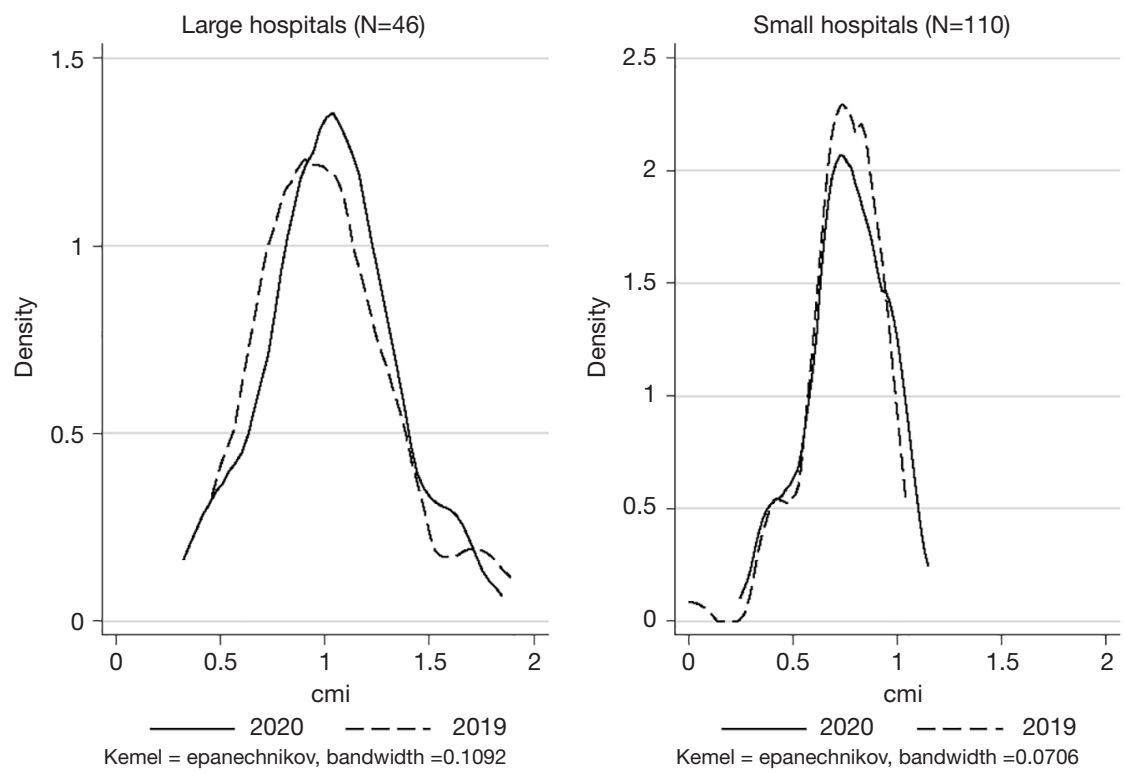

Figure 2 The average CMI distributions of 156 hospitals on 2019 and 2020 for large hospitals and small hospitals from January to October. For both of large hospitals and small hospitals, their CMI density graph peak right shifted slightly in 2020 compared to 2019 . The average increase in the ratio for small hospitals $(3.08 \%)$ was a slightly higher than that of large hospitals $(2.43 \%)$. Nevertheless, neither of the increases were significant. CMI, case mix index.

visits and discharges. Additionally, the market share showed substantial monthly fluctuation. Therefore, we taken a hospital in a given month, such as January or February, as an individual item in our statistical analysis.

\section{Discussion}

\section{The primary findings of this study}

Using the hospital-based longitudinal data of all public hospitals in Shanghai from January 2018 to July 2020, we conducted a study on the short-term surplus of healthcare supply capacity in all hospitals due to the COVID-19 pandemic in Shanghai and compared the market share change differences between large hospitals and small hospitals during and after COVID-19. We speculated that pandemic control measures would affect patients' careseeking preferences and that the postpandemic period would see a huge reduction in health service as restrictions on patients were lifted.

According to the results presented above, due to the shock of COVID-19, all health services were substantially reduced, for the whole 2020, which led to a large surplus of the health service supply capacity in hospitals in Shanghai during this period. Compared to the small hospitals, the large hospitals suffered a more severe reduction in market share at the height of the pandemic. The reduction was more considerable for the discharge services and the nonlocal patients. As for the postpandemic period, the retaliatory rebounds of the large hospitals' market shares were significant for outpatient income, and numbers of visits and discharges, particularly for the overall and local patients. This indicates that the large hospitals could have poached local patients from the small hospitals to compensate for the surplus of the healthcare supply capacity. An alternative explanation for the relatively increased market share was the reduction of unnecessary health services typically provided by small hospitals. However, the comparison of the CMI from January to October in 2019 and 2020 indicated that this alternative could be rejected.

\section{The health service supply capacity surplus in hospitals due to the COVID-19}

This study showed that the COVID-19 brought about a substantial reduction in the health service of public hospitals in Shanghai, same as previous studies on China and other counties (21,31-34). Therefore, the large hospitals had a massive supply capacity surplus which could be filled by 

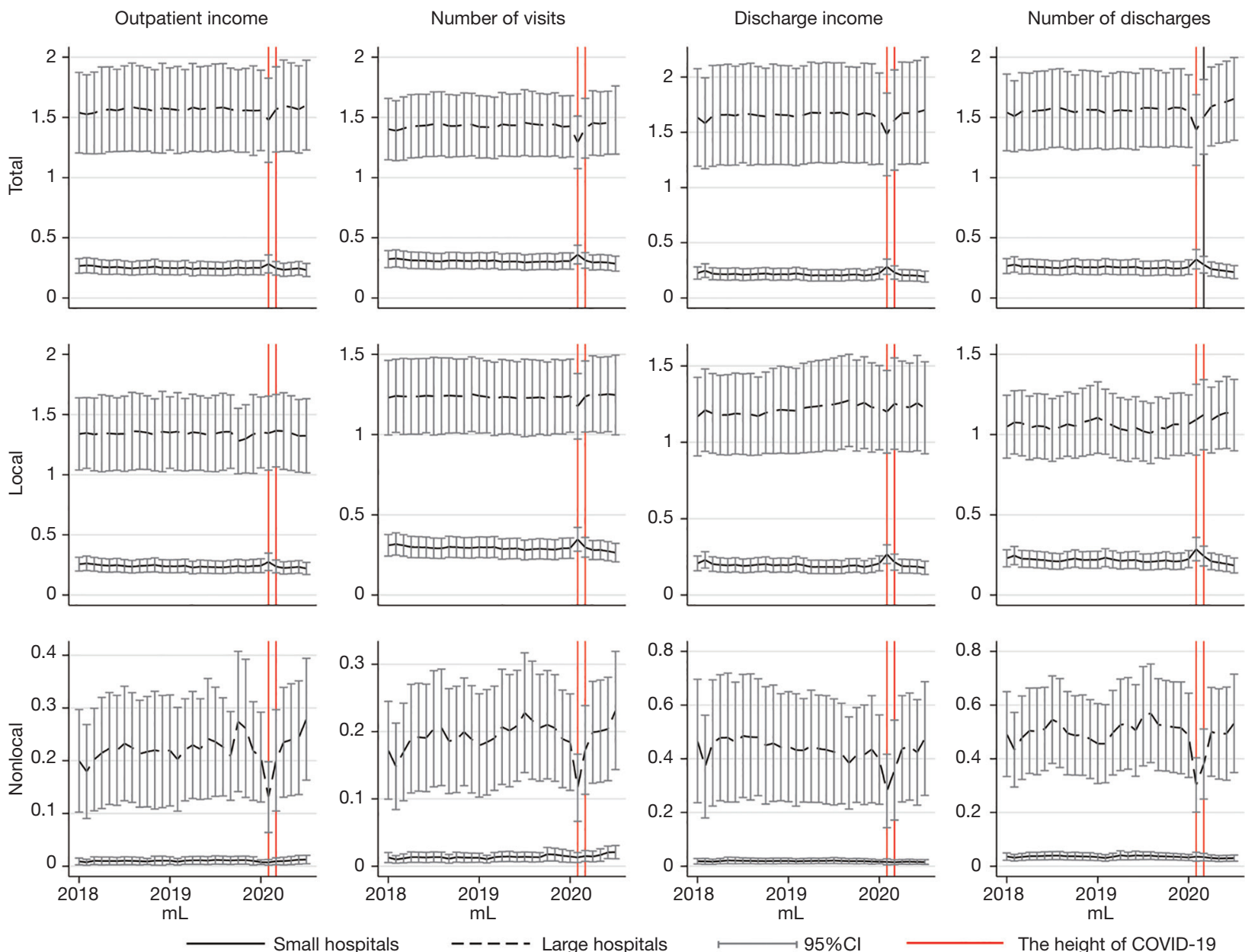

Figure 3 The average market share of large hospitals [46] and small hospitals [110] from January 2018 to July 2020 according to visits and discharge healthcare services for total, local, and nonlocal patients. For both the outpatient service and discharge service, the market share distribution between the large and small hospitals for total and local patients was more stable than that for the nonlocal patients. In the 31 month-year depicted in the figure, the market share was relatively stable, but fluctuated at the height of the COVID-19 pandemic beginning in February 2020.

accepting a large number of patients previously treated in small hospitals; that is, the large hospitals resorted to poaching patients from the small hospitals. The massive supply capacity surplus is the precondition for the obvious siphon effect. This reduction, which persisted for the entirety of 2020, might have been the result of a number of causes, those have been discussed in our previous study (27). Including the population control measures, treatment postponed, changes in the disease's spectrum during this pandemic period and the reduction on potential overtreatment. The potential existence of treatment postponed may lead to terrible health lost to patients in need $(31,32)$. It indicated that the health care suppliers should establish a quick response mechanism to prevent from those lost due to the future nature shock.

\section{Large hospitals lost their market share under the COVID-19 pandemic conditions}

We found that large hospitals' market share in healthcare service reduced more than that of the small hospitals at the height of the COVID-19 period. Different from the nonlocal health demand, the number of local residences in Shanghai was relatively stable. In the local market, we 
did observe the significant market share shift from large hospitals to small hospitals in the health services for the outpatient services. This suggests that the small hospitals served the patients that used to be treated in the large hospitals. However, this change might have only been relevant for minor diseases that can be treated by outpatient services. It remains us to reconsider the rationality of the market share of the healthcare delivery system in China.

Under normal conditions, most patients in China prefer to visit large hospitals even for common and minor illnesses, as they can freely choose which doctors and medical institutions to visit $(18,19,35)$. These might be due to the COVID-19 pandemic increasing the care-seeking cost of large hospitals, which may include the risk of being infected and transportation convenience (18). This suggests that a way to change the current healthcare delivery system into a PHC-based system is by increasing the cost gap between large hospitals and small hospitals.

\section{The comparison of the market share of the local and nonlocal patients proves the presence poaching behavior}

In this study, we found that large hospitals took the market share of health service from the small hospitals during the postpandemic period when there was a surplus in their healthcare supply capacity and a large amount of patients served by small hospitals. During the post-COVID 19 period, the significant market share shifts of local patients from small hospitals to large hospitals on outpatient and inpatient services volume were observed. The shift was more substantial for discharge services and surgery services. This may have occurred due to patients being more likely to choose larger hospitals when they needed more complex treatment $(18,35)$. This means the patients might be more likely to choose larger hospitals for conditions perceived to be nonminor diseases. As there was no strict referral system and a lax medical insurance restriction, the patients can choose which doctors and medical institutions to visit freely $(18,19,35)$. Before the pandemic, the large hospitals in China were always crowded, and some patients left these hospitals due to this crowding (3).

The differences in market share changes in the local patients and the nonlocal patients supported the existence of this poaching phenomenon (i.e., the siphon effect). Different from the local patients, who chose small hospitals and large hospitals for their minor diseases and severe diseases, respectively, most nonlocal health services are usually provided by large hospitals $(24,25)$. There was no available nonlocal patient resources for large hospitals to poach after the control measures were relaxed.

Generally, the large hospitals poached the market share from small hospitals, by treating the local patients' minor diseases that had previously been treated in small hospitals. This was supported by a greater increase in the percentage of the small hospitals' CMI.

\section{The implications of the findings}

The pandemic will pass, but its effects will last. Going beyond just the cause of disease or death, pandemics can impact many areas, chiefly psychological, social, and economic ones $(36,37)$. The more important thing is that what can be learned from these difficult times. What we have in our study might be useful for the construction of the PHC-based integrated delivery system for the whole healthcare system. First, the existence of unnecessary healthcare was clear before the COVID-19 pandemic, which provided us a rare opportunity to observe it in a real-world scenario $(20,38)$. Further studies should be conducted based on the reduction of health services during the pandemic to find what should be eliminated and what should be made up to improve patients' health. Second, the patients that used to be served by large hospitals turned to seek healthcare service from small hospitals under pandemic conditions, which was a desirable change to construct the PHC-based integrated delivery system. It showed that changing the factors affecting patients' care-seeking cost, such as transportation convenience and cost of referral, would be one plausible way to reduce unnecessary treatment and improve the hierarchical diagnosis and treatment model. Finally, some caution should be held on the unreasoning health expansion and even the ongoing hospital vertical integration under governmental intervention and the emergence of much large hospitals under the existence of the "siphon effect". This point was mentioned in the previous official document and study (3,39).

\section{Strength and limitations}

The siphon effect has long been discussed, but no statistical analysis has been conducted to verify the existence of this effect. Like a ghost, everyone talks about it, but no one has yet proven its existence. This paper conducted a statistical analysis on the natural experiment of COVID-19 to confirm the existence of the siphon effect: large hospitals do poach patients from the small ones if they have a supply capacity 
surplus. Our findings can serve as a powerful evidence to be considered when discussing the ideal size of hospitals, especially in countries like China which do not have strict referral restrictions.

Nonetheless, some limitations were unavoidable in this study, and are described below. First, the statistical model was modified from the traditional DID model, but both the control group (small hospitals) and the treated group (large hospitals) were affected by the pandemic. The effect we intended to analyze is the patient-absorbing ability of large hospitals compared to the small hospitals under COVID-19 pandemic conditions, rather than the effect of COVID-19 itself. Thus, there was little doubt concerning the validation of the model we used. However, a better choice would be to choose large hospitals with no health service capacity surplus as the control group. However, due to the realworld situation, it was too difficult to obtain data in this manner. A second limitation was the number of years: the sample we used was short panel data, so the pseudmodel constructed could note include alternative months as the intervention period. Third, the monthly CMI we presented is the average level of each month rather than the original CMI level of each hospital in each month due to the availability of data. The nonchanged CMI during this period could only be used to reject the assumption of a reduction in unnecessary health service and not help prove that large hospitals directly poach minor-issue health service seekers from the small hospitals.

\section{Conclusions}

In this study, we found a dramatic reduction in all healthcare services in Shanghai's public healthcare delivery system and a pattern of large hospitals with a large supply capacity surplus poaching patients from other small hospitals. On the one hand, the market share losses of the large hospitals at the height of the COVID-19 pandemic indicate that with higher care-seeking cost in the large hospitals, some healthcare services that had been provided by large hospitals were supplied by small hospitals. This reminds us of the irrationality of the current market share in healthcare delivery system. We clearly observed the large hospitals' siphon effect, which means the large hospitals can poach patients from small hospitals if they have the supply capacity surplus. To reconstruct the PHC-based integrated health delivery system, the irrational expansion of large hospitals should be controlled and policies should be implemented to induce patients to use primary care.

\section{Acknowledgments}

Funding: None.

\section{Footnote}

Reporting Checklist: The authors have completed the STROBE reporting checklist. Available at https://dx.doi. org/10.21037/atm-21-2793

Data Sharing Statement: Available at https://dx.doi. org/10.21037/atm-21-2793

Conflicts of Interest: All authors have completed the ICMJE uniform disclosure form (available at https://dx.doi. org/10.21037/atm-21-2793). The authors have no conflicts of interest to declare.

Ethical Statement: The authors are accountable for all aspects of the work in ensuring that questions related to the accuracy or integrity of any part of the work are appropriately investigated and resolved. The study was conducted in accordance with the Declaration of Helsinki (as revised in 2013). The study was approved by the registration number of Medical Ethics Committee of Shanghai Health Development Research Center (No.: 2021002). The need for written patient consent was waived because of the observational nature of this study, the subject can no longer be found, and the research project does not involve personal privacy or commercial interests.

Open Access Statement: This is an Open Access article distributed in accordance with the Creative Commons Attribution-NonCommercial-NoDerivs 4.0 International License (CC BY-NC-ND 4.0), which permits the noncommercial replication and distribution of the article with the strict proviso that no changes or edits are made and the original work is properly cited (including links to both the formal publication through the relevant DOI and the license). See: https://creativecommons.org/licenses/by-nc-nd/4.0/.

\section{References}

1. Barber SL, Borowitz M, Bekedam H, et al. The hospital of the future in China: China's reform of public hospitals and trends from industrialized countries. Health Policy Plan 2014;29:367-78.

2. Wang S. State policy orientation, extractive capacity and 
the equality of healthcare in urban China. Social Sciences in China 2005;6:101-20.

3. Sun Z, Wang S, Barnes SR. Understanding congestion in China's medical market: an incentive structure perspective. Health Policy Plan 2016;31:390-403.

4. General Office of the State Council of the People's Republic of China. General Office of the State Council of the People's Republic of China Opinions on deepening the reform of the medical and health care system. General Office of the State Council of the People's Republic of China. 2009. Available online: http://www.gov.cn/ jrzg/2009-04/06/content_1278721.htm (Accessed May 27 2021).

5. Jiang X, He P, Zhu D, et al. Different impacts of the zeromarkup drug policy on county general and traditional Chinese medicine hospitals: evidence from Shandong province, China. Int J Equity Health 2020;19:219.

6. Yip W, Fu H, Chen AT, et al. 10 years of health-care reform in China: progress and gaps in Universal Health Coverage. Lancet 2019;394:1192-204.

7. Li H, Liu K, Gu J, et al. The development and impact of primary health care in China from 1949 to 2015: A focused review. Int J Health Plann Manage 2017;32:339-50.

8. National Health Commission of the People's Republic of China. China Health Statistics Yearbook 2020. Beijing: Peking Union Medical College Press, 2021.

9. Kao C, Pang RZ, Liu ST, et al. Optimal expansion paths for hospitals of different types: viewpoint of scope economies and evidence from Chinese hospitals. Eur J Oper Res 2021;289:628-38.

10. Cerullo M, Sheckter CC, Canner JK, et al. Is Bigger Better?: The Effect of Hospital Consolidation on Index Hospitalization Costs and Outcomes Among Privately Insured Recipients of Immediate Breast Reconstruction. Ann Surg 2019;270:681-91.

11. Ozcan YA, Luke RD. A national study of the efficiency of hospitals in urban markets. Health Serv Res 1993;27:719-39.

12. Lu L, Pan J. Does hospital competition lead to medical equipment expansion? Evidence on the medical arms race. Health Care Manag Sci 2021;24:582-96.

13. Noether M. Competition among hospitals. J Health Econ 1988;7:259-84.

14. Wu D, Lam TP. Underuse of Primary Care in China: The Scale, Causes, and Solutions. J Am Board Fam Med 2016;29:240-7.

15. Pan J, Qin X, Hsieh CR. Is the pro-competition policy an effective solution for China's public hospital reform?
Health Econ Policy Law 2016;11:337-57.

16. Kangovi S, Barg FK, Carter T, et al. Understanding why patients of low socioeconomic status prefer hospitals over ambulatory care. Health Aff (Millwood) 2013;32:1196-203.

17. Varkevisser M, van der Geest SA, Schut FT. Do patients choose hospitals with high quality ratings? Empirical evidence from the market for angioplasty in the Netherlands. J Health Econ 2012;31:371-8.

18. Liu Y, Zhong L, Yuan S, et al. Why patients prefer highlevel healthcare facilities: a qualitative study using focus groups in rural and urban China. BMJ Glob Health 2018;3:e000854.

19. Hu Y, Zhang Z. Skilled doctors in tertiary hospitals are already overworked in China. Lancet Glob Health 2015;3:e737.

20. Kim EJ, Marrast L, Conigliaro J. COVID-19: Magnifying the Effect of Health Disparities. J Gen Intern Med 2020;35:2441-2.

21. Wang H, Wu J, Wei Y, et al. Surgical Volume, Safety, Drug Administration, and Clinical Trials During COVID-19: Single-center Experience in Shanghai, China. Eur Urol 2020;78:120-2.

22. Li H, Yu G, Duan H, et al. Changes in Children's Healthcare Visits During Coronavirus Disease-2019 Pandemic in Hangzhou, China. J Pediatr 2020;224:146-9.

23. Wu Z, McGoogan JM. Characteristics of and Important Lessons From the Coronavirus Disease 2019 (COVID-19) Outbreak in China: Summary of a Report of 72314 Cases From the Chinese Center for Disease Control and Prevention. JAMA 2020;323:1239-42.

24. Jin C, Wang L, Hu S, et al. The study on the process and impact of external-care-seeking behavior in Shanghai. Open J Prev Med 2015;5:103.

25. Li F, Gu S, Zhu B, et al. Analysis on the Status of NonResidents'Medical Service in Shanghai under the Perspective of Improving Health Ex-pense Accounting. Chinese Health Economics 2020;39:50-3.

26. Zhou Y, Xu R, Hu D, et al. Effects of human mobility restrictions on the spread of COVID-19 in Shenzhen, China: a modelling study using mobile phone data. Lancet Digit Health 2020;2:e417-24.

27. Chen Y, Cai M, Li Z, et al. Impacts of the COVID-19 Pandemic on Public Hospitals of Different Levels: SixMonth Evidence from Shanghai, China. Risk Management and Healthcare Policy 2021. In Press.

28. Mendez CM, Harrington DW, Christenson P, et al. Impact of hospital variables on case mix index as a marker 
of disease severity. Popul Health Manag 2014;17:28-34.

29. Dimick JB, Ryan AM. Methods for evaluating changes in health care policy: the difference-in-differences approach. JAMA 2014;312:2401-2.

30. Doudchenko N, Imbens GW. Balancing, regression, difference-in-differences and synthetic control methods: a synthesis. National Bureau of Economic Research, 2016. doi: 10.3386/w22791.

31. Lantelme P, Couray Targe S, Metral P, et al. Worrying decrease in hospital admissions for myocardial infarction during the COVID-19 pandemic. Arch Cardiovasc Dis 2020;113:443-7.

32. Diegoli H, Magalhães PSC, Martins SCO, et al. Decrease in Hospital Admissions for Transient Ischemic Attack, Mild, and Moderate Stroke During the COVID-19 Era. Stroke 2020;51:2315-21.

33. Kapsner LA, Kampf MO, Seuchter SA, et al. Reduced Rate of Inpatient Hospital Admissions in 18 German University Hospitals During the COVID-19 Lockdown. Front Public Health 2021;8:594117.

34. Birkmeyer JD, Barnato A, Birkmeyer N, et al. The Impact Of The COVID-19 Pandemic On Hospital Admissions In The United States. Health Aff (Millwood)
2020;39:2010-7.

35. Cui C, Zuo X, Wang Y, et al. A comparative study of patients' satisfaction with different levels of hospitals in Beijing: why do patients prefer high-level hospitals? BMC Health Serv Res 2020;20:643.

36. Chakraborty I, Maity P. COVID-19 outbreak: Migration, effects on society, global environment and prevention. Sci Total Environ 2020;728:138882.

37. Haleem A, Javaid M, Vaishya R. Effects of COVID-19 pandemic in daily life. Curr Med Res Pract 2020;10:78-9.

38. Moynihan R, Johansson M, Maybee A, et al. Covid-19: an opportunity to reduce unnecessary healthcare. BMJ 2020;370:m2752.

39. General Office of the State Council of the People's Republic of China. The General Office of the State Council of the People's Republic of China issued on deepening medical and health care notice on the key tasks of institutional reform in 2014. 2014. Available online: http://www.gov.cn/zhengce/content/2014-05/28/ content_8832.htm (Accessed May 27 2021).

(English Language Editor: J. Gray)
Cite this article as: Chen Y, Wang L, Cui X, Xu J, Xu Y, Yang Z, Jin C. COVID-19 as an opportunity to reveal the impact of large hospital expansion on the healthcare delivery system: evidence from Shanghai, China. Ann Transl Med 2021;9(16):1297. doi: 10.21037/atm-21-2793 


\section{Supplementary}

Table S1 The COVID-19 pandemic's effect on the public hospitals' total medical revenue and surgery number market shares (156 hospitals examined in February and March in 2018, 2019, and 2020)

\begin{tabular}{|c|c|c|c|c|c|c|}
\hline Variables & \multicolumn{3}{|c|}{ Total medical revenue } & \multicolumn{3}{|c|}{ Number of surgeries } \\
\hline \multicolumn{7}{|l|}{ Hospital type } \\
\hline TCM & $-0.440^{\star \star \star}(0.121)$ & $-0.303^{\star \star \star}(0.0887)$ & $-0.137^{\star * \star}(0.0425)$ & $-0.528^{\star \star *}(0.126)$ & $-0.367^{\star \star \star}(0.0877)$ & $-0.161^{\star \star \star}(0.0517)$ \\
\hline $\begin{array}{l}\text { Specialized } \\
\text { hospitals }\end{array}$ & $-0.593^{\star \star \star}(0.0818)$ & $-0.526^{\star \star \star}(0.0601)$ & $-0.0673^{\star \star}(0.0288)$ & $-0.489^{\star * \star}(0.0857)$ & $-0.425^{\star \star \star}(0.0595)$ & $-0.0638^{\star}(0.0351)$ \\
\hline Pandemic & $0.0190(0.0128)$ & $0.0211^{*}(0.0110)$ & $-0.00202(0.00764)$ & $0.0138(0.0259)$ & $0.0112(0.0196)$ & $0.00262(0.0122)$ \\
\hline Treat ${ }^{\star}$ pandemic & $-0.0763^{\star \star \star}(0.0236)$ & $-0.00335(0.0203)$ & $-0.0730^{\star \star \star}(0.0141)$ & $-0.0487(0.0478)$ & $0.0817^{\star \star}(0.0362)$ & $-0.130^{\star \star \star}(0.0224)$ \\
\hline Constant & $0.583^{\star \star \star}(0.0653)$ & $0.519^{\star \star \star}(0.0480)$ & $0.0640^{\star \star \star}(0.0231)$ & $0.526^{\star \star \star}(0.0687)$ & $0.434^{\star \star \star}(0.0478)$ & $0.0914^{\star \star \star}(0.0282)$ \\
\hline $\begin{array}{l}\text { Number of } \\
\text { hospitals*month }\end{array}$ & 312 & 312 & 312 & 312 & 312 & 312 \\
\hline
\end{tabular}

Standard errors in parentheses. * $\mathrm{P}<0.1 ;{ }^{* \star}, \mathrm{P}<0.05 ;{ }^{* \star \star}, \mathrm{P}<0.01$. * (in first column) means interaction operator. TCM, traditional Chinese medicine.

Table S2 The COVID-19 postpandemic effect on the public hospitals' total medical revenue and surgery number market shares (156 hospitals examined in April and May in 2018, 2019, and 2020)

\begin{tabular}{|c|c|c|c|c|c|c|}
\hline Variables & \multicolumn{3}{|c|}{ Total medical revenue } & \multicolumn{3}{|c|}{ Number of surgeries } \\
\hline \multicolumn{7}{|l|}{ Hospital type } \\
\hline TCM & $-0.443^{\star \star \star}(0.129)$ & $-0.280^{\star \star \star}(0.0896)$ & $-0.163^{\star \star \star}(0.0494)$ & $-0.506^{\star \star \star}(0.127)$ & $-0.330^{\star \star \star}(0.0805)$ & $-0.176^{\star \star \star}(0.0597)$ \\
\hline $\begin{array}{l}\text { Specialized } \\
\text { hospitals }\end{array}$ & $-0.570^{\star \star \star}(0.0876)$ & $-0.490^{\star \star \star}(0.0608)$ & $-0.0804^{\star \star}(0.0335)$ & $-0.530^{\star \star \star}(0.0860)$ & $-0.438^{\star \star \star}(0.0546)$ & $-0.0917^{\star \star}(0.0405)$ \\
\hline Ppandemic & $-0.00857(0.00555)$ & $-0.00664(0.00673)$ & $-0.00192(0.00584)$ & $-0.0175(0.0191)$ & $-0.00199(0.0162)$ & $-0.0155(0.00977)$ \\
\hline Treat*ppandemic & $0.0224^{\star \star}(0.0102)$ & $0.0287^{\star *}(0.0124)$ & $-0.00626(0.0108)$ & $0.0576(0.0352)$ & $0.0726^{\star \star}(0.0299)$ & $-0.0150(0.0180)$ \\
\hline Constant & $0.559^{\star \star \star}(0.0697)$ & $0.483^{\star \star \star}(0.0484)$ & $0.0753^{\star \star \star}(0.0267)$ & $0.541^{\star \star \star}(0.0688)$ & $0.428^{\star \star \star}(0.0438)$ & $0.113^{\star \star \star}(0.0324)$ \\
\hline $\begin{array}{l}\text { Number of } \\
\text { hospitals*month }\end{array}$ & 312 & 312 & 312 & 312 & 312 & 312 \\
\hline
\end{tabular}

Standard errors in parentheses. ${ }^{\star \star}, \mathrm{P}<0.05 ;{ }^{\star \star \star}, \mathrm{P}<0.01 .{ }^{*}$ (in first column) means interaction operator. TCM, traditional Chinese medicine. 